\title{
Research Paper: Assessment of Risk Factors and the Effect of Drug Abuse on the Incidence of Ischemic Heart Disease in Patients Less Than 40 Years Old
}

\author{
Javad Karimi ${ }^{1}$, Mohamadreza Maghsoudi ${ }^{1}$, Lida Shojaei Arani ${ }^{2}$, Shahrooz Yazdani ${ }^{3}$, Nami Mohammadian Khonsari ${ }^{4}$, Kiumars Bahmani ${ }^{5}$, \\ Hoorvash Faraji Dana ${ }^{2 *}$ iD \\ 1. Department of Emergency, Faculty of Emergency Medicine \& Toxicology, Alborz University of Medical Science, Karaj, Iran. \\ 2. Department of Clinical Toxicology, Loghman Hakim Hospital Poison Center, Faculty of Medicine, Shahid Beheshti University of Medical Sciences, \\ Tehran, Iran. \\ 3. Cardiovascular Research Center, Alborz University of Medical Sciences, Karaj, Iran. \\ 4. Research Committee, Alborz University of Medical Sciences, Karaj, Iran. \\ 5. Department of Pharmacology and Toxicology, School of Pharmacy, Shahid Beheshti University of Medical Science, Tehran, Iran.
}

$\begin{aligned} & \text { Use your device toscan } \\ & \text { and read the article online }\end{aligned}$
Citation: Karimi J, Maghsoudi MR, Shojaei Arani L, Yazdani S, Mohammadian Khonsari N, Bahmani K, Faraji Dana H. Assess-
ment of Risk Factors and the Effect of Drug Abuse on the Incidence of Ischemic Heart Disease in Patients Less Than 40 Years Old.
International Journal of Medical Toxicology and Forensic Medicine. 2021; 11(1):31751. https://doi.org/10.32598/ijmtfm.v11i.31751
doij https://doi.org/10.32598/ijmtfm.v11i.31751

Article info:

Received: 13 Aug 2020

First Revision: 12 Sep 2020

Accepted: 11 Oct 2020

Published: 21 Apr 2021

\section{ABSTRACT}

Background: in this study, we examined the risk factors and the effects of substance abuse on the incidence of ischemic heart disease in patients less than 40 years old in Shahid Rajaei Hospital in Karaj from 2019-2020.

Methods: This case-control study was done on 70 patients in the cases and 70 cases in the control groups. All demographic data, including age, gender, place of residence, weight, height, body mass index, Cardiovascular (CVD) risk factors, including hypertension, high levels of blood fats, diabetes, a history of smoking cigarettes, tobacco, crystal meth, and cocaine, alcohol consumption, as well as a history of taking supplements for bodybuilding, and sex-enhancing drugs were obtained. Afterward, blood levels of glucose and fats were evaluated and urine analysis for the presence of drugs, such as amphetamine, methamphetamine, buprenorphine, benzodiazepines, cannabinoids, cocaine, morphine, methadone, tramadol, and Tricyclic Antidepressants (TCA) was done. SPSS software v. 22 was used for data analysis.

Results: Among the studied underlying factors and drugs, family history, high blood pressure, diabetes, smoking, and Low-density Lipoprotein (LDL) levels above $130 \mathrm{mg} / \mathrm{dL}$ were significantly associated with a higher risk of acute Myocardial Infarction $(\mathrm{MI})(\mathrm{P}<0.05)$. Interestingly, alcohol consumption and the use of tobacco, opium, methadone, heroin, cocaine, cannabis, amphetamines, methamphetamine, tramadol, benzodiazepines, TCA, buprenorphine, and anabolic steroids were not significantly associated with acute MI under 40 years $(\mathrm{P}>0.05)$.

Conclusion: according to the results of the present study, it seems that a positive family history of MI under the age of 55, hypertension, diabetes, smoking, and LDL levels above $130 \mathrm{mg} / \mathrm{dL}$ are more significant risk factors for acute $\mathrm{MI}$ in patients under 40 years of age in comparison with the consumption of alcohol and the use of hookah, opium, methadone, heroin, cocaine, cannabis, amphetamine, methamphetamine, tramadol, benzodiazepines, TCA, buprenorphine, and anabolic steroids. It should be noted that further studies in this area are recommended.

\section{Keywords:}

Myocardial infarction, Drugs, Cardiovascular Disease
" Corresponding Author:

Hoorvash Faraji Dana, MD.

Address: Department of Clinical Toxicology, Loghman Hakim Hospital Poison Center, Faculty of Medicine, Shahid Beheshti University of Medical Sciences, Tehran, Iran.

Tel: +98 (261) 34552001

E-mail:f.drhoorvash@yahoo.com 


\section{Introduction}

schemic heart disease is common worldwide and is recognized as one of the leading causes of disability and mortality, accounting for $12.7 \%$ of deaths in all societies and countries and a significant cause of death in most societies [1]. According to studies conducted in Iran, ischemic heart disease has a growing trend [2]. The acute coronary syndrome is a common manifestation of ischemic heart disease, which includes unstable angina, and Myocardial Infarction (MI) without elevation, nonST segment elevation myocardial infarction, and STsegment Elevation Myocardial Infarction (STEMI). MI can be fatal and may lead to sudden death [3]. Although MI mainly occurs in people over the age of 45 , it can be seen in younger people, as well $[1,2,4]$. An increasing number of younger patients are being hospitalized with a diagnosis of the acute coronary syndrome [2].

According to comprehensive studies, the prevalence of acute coronary syndrome in people under 40 to 45 years of age is reported to be $3 \%$ to $10 \%$ [5]. Although the prevalence of ischemic heart disease is lower in comparison with the senior population, its incidence at a younger age leads to disability and significant psychological effects with a higher economic burden for the patient and his family [6, 7]. Risk factors associated with cardiovascular diseases include hypertension, hyperlipidemia, smoking, diabetes, age, family history of premature heart disease, male gender, and recently acquired immunodeficiency virus (HIV), according to the Framingham Heart Study [8]. Nonetheless, ischemic heart disease at young ages can be the result of the tendency to high - fat diets and an unhealthy lifestyle, which leads to an increase in the incidence of metabolic syndrome, hypertension, and high blood sugar.

Further studies indicate an increased incidence of known risk factors in the Framingham study among young people with coronary artery disease. For example, smoking as one of the most important risk factors for cardiovascular disease is increasing among young people and adolescents in the community [9]. In addition, the incidence of obesity among young people has increased in recent decades [4]. A similar study was conducted in China on 31 young patients with ischemic heart disease and the most important risk factors were male gender and smoking [10].

Non-atherosclerotic factors, including cocaine use, hypercoagulative state, nephrotic syndrome, and connective tissue diseases can also cause coronary artery disease in this age group [11]. In recent decades, the use of hormonal drugs and sports supplements have become common among the youths, and the adverse effects of these drugs on the incidence of cardiovascular events and heart function have been proven in various studies [12]. Narcotics, such as methadone and tramadol are other substances that are abused and have a detrimental effect on the cardiovascular system [13].

Marijuana is another risk factor for cardiovascular accidents and should be considered due to its high consumption by young people [14]. Hookah is also known as one of the most widely used tobaccos in Iran, and its consumption increases blood pressure and heart rate and the risk of cardiovascular accidents [15]. Amphetamines and methamphetamines are among the other substances that have been proven to increase the risk of all cardiac pathologies, including ischemic heart disease and their use is increasing by the young population $[16,17]$.

Although few studies have been conducted on the benefits of alcohol on the cardiovascular system, the adverse effects of alcohol consumption on the cardiovascular system have been reported in many studies, and alcohol consumption is still recognized as a risk factor in cardiovascular events [18]. Despite the lower prevalence of cardiac ischemia among young people, the adverse effects of such events have had their effects on the individual, society, and health system. By identifying known risk factors as well as lesser-known factors among the young patients compared with the elderly patients, it is possible to reduce the increase in ischemic heart disease in the young population in the near future.

Despite studies conducted in some countries, there are few studies in Iran on the identification of risk factors for acute coronary syndrome in people younger than 40 years compared with elderly patients. Also, the identification and correction of these factors lead to a reduction in the incidence of the acute coronary syndrome, Therefore, in this study, we examined the risk factors for the disease and assessed the effect of substance abuse on the incidence of ischemic heart disease in patients less than 40 years old.

\section{Materials and Methods}

This case-control study, after being evaluated by the Ethics in Research Committee of Alborz University of Medical Sciences (IR.ABZUMS.REC.1398.220). Patients under the age of 40 with acute coronary syndrome referred to Shahid Rajaei Hospital in Karaj from April 2019 to March 2020 were randomly selected. Inclusion criteria for the case group were as following: age between 
18 to 40 years, diagnosis of acute coronary syndrome using diagnostic criteria by a specialist, and the patient's consent to participate in the study. The exclusion criteria for both study groups were genetic and chromosomal diseases as well as the age of younger than 18 years.

The control group was selected from non-cardiac patients and the study groups were evaluated for four months. At first, the study was explained to the participants, and written consent was obtained from the patients. They were informed about voluntary participation in the study, the right to leave the study at any time, and the use of their data for public use only. Afterward, demographic information, including age, sex, place of residence, nationality, weight, height, and Body Mass Index (BMI) was obtained.

Table 1. Demographic and clinical characteristics of the participants

\begin{tabular}{|c|c|c|c|c|c|}
\hline \multirow{2}{*}{ Variables } & \multicolumn{2}{|r|}{ Cases } & \multicolumn{2}{|c|}{ Controls } & \multirow{2}{*}{$\mathbf{P}$} \\
\hline & Min to Max & Mean $\pm S D$ & Min to Max & Mean $\pm S D$ & \\
\hline Age $(y)$ & 22 to 40 & $33.11 \pm 3.58$ & 25 to 40 & $34.21 \pm 3.81$ & 0.057 \\
\hline Height (cm) & 150.8 to 198.1 & $172.47 \pm 12.47$ & 149.4 to 197 & $170.21 \pm 12.2$ & 0.28 \\
\hline Weight (kg) & 54 to 113 & $78.67 \pm 12.32$ & 48 to 100 & $74.35 \pm 14.03$ & 0.335 \\
\hline $\mathrm{BMI}\left(\mathrm{kg} / \mathrm{m}^{2}\right)$ & 22.83 to 33.50 & $26.32 \pm 1.58$ & 19.28 to 27.71 & $25.45 \pm 2.71$ & 0.99 \\
\hline Male to female ratio & \multicolumn{2}{|r|}{$41 / 29$} & \multicolumn{2}{|c|}{$39 / 35$} & 0.86 \\
\hline Living in urban/rural areas & \multicolumn{2}{|r|}{$65 / 5$} & \multicolumn{2}{|c|}{$62 / 8$} & 0.38 \\
\hline $\begin{array}{l}\text { Family history of myocardial } \\
\text { infarction under the age of } 55\end{array}$ & \multicolumn{2}{|r|}{14} & \multicolumn{2}{|c|}{4} & $0.01^{*}$ \\
\hline Presence of hypertension & \multicolumn{2}{|r|}{18} & \multicolumn{2}{|c|}{8} & $0.03^{*}$ \\
\hline Presence of diabetes & \multicolumn{2}{|r|}{11} & \multicolumn{2}{|c|}{3} & $0.02^{*}$ \\
\hline Alcohol consumption & \multicolumn{2}{|r|}{5} & \multicolumn{2}{|c|}{6} & 0.75 \\
\hline Smoking cigarette & \multicolumn{2}{|r|}{36} & \multicolumn{2}{|c|}{21} & $0.01^{*}$ \\
\hline Smoking hookah & \multicolumn{2}{|r|}{10} & \multicolumn{2}{|c|}{7} & 0.43 \\
\hline Urine tests positive for drugs & \multicolumn{2}{|r|}{6} & \multicolumn{2}{|c|}{3} & 0.3 \\
\hline Using Methadone & \multicolumn{2}{|r|}{5} & \multicolumn{2}{|c|}{3} & 0.4 \\
\hline Using Heroin & \multicolumn{2}{|r|}{2} & \multicolumn{2}{|c|}{0} & 0.15 \\
\hline Using Cocaine & \multicolumn{2}{|r|}{1} & \multicolumn{2}{|c|}{0} & 0.31 \\
\hline Using Cannabis & \multicolumn{2}{|r|}{7} & \multicolumn{2}{|c|}{4} & 0.31 \\
\hline Using Methamphetamine & \multicolumn{2}{|r|}{3} & \multicolumn{2}{|c|}{1} & 0.31 \\
\hline Using Tramadol & \multicolumn{2}{|r|}{6} & & & 0.14 \\
\hline Using Benzodiazepines & & 3 & & & 0.3 \\
\hline $\begin{array}{l}\text { Using Tricyclic Antidepressants } \\
\text { (TCAs) }\end{array}$ & & 2 & & & 0.55 \\
\hline Using Buprenorphine & & 0 & & & 0.31 \\
\hline Using Anabolic steroids & & 7 & & & 0.08 \\
\hline Using sex-enhancing drugs & & 1 & & & \\
\hline
\end{tabular}


Cardiovascular risk factors, including high blood pressure, hyperlipidemia, diabetes, family history, smoking cigarette, hookah, crystal, and cocaine, alcohol use, and the use of supplements and bodybuilding drugs and sex-enhancing drugs were assessed by interviews with the participants and blood and urine tests. Laboratory parameters were prepared and completed using the information in the patients' records. The sample size was calculated to be 140 patients with a $95 \%$ coefficient, an error of 0.05 , and a power of $80 \%$. Obesity was defined as a BMI $\geq 27 \mathrm{~kg} / \mathrm{m}^{2}$, hypertension as blood pressure of above 140/90 $\mathrm{mmHg}$, hyperlipidemia as cholesterol $>200 \mathrm{mg} / \mathrm{dL}$, Low-density Lipoprotein (LDL) >100 mg/ $\mathrm{dL}$, High-density Lipoprotein (HDL) $<40 \mathrm{mg} / \mathrm{dL}$ and Triglyceride $(\mathrm{TG})>200 \mathrm{mg} / \mathrm{dL}$, and diabetes as fasting blood glucose above 126 or random blood glucose above 200 or hemoglobin A1C more than 6.5\% [19]. SPSS software v. 24 was used for data analysis using
Chi-square test, independent t-test and P-values of less than 0.05 were considered significant.

\section{Results}

The demographic characteristics of the case and control groups are summarized in Table 1. Family history of MI under the age of less than 55, the presence of hypertension and diabetes, and smoking were more observed in the case group and there was no significant difference between the two groups for the other parameters.

Regarding the laboratory test data, none of the factors, such as hemoglobin, creatinine, TG, total cholesterol, HDL, and uric acid showed a significant difference between the two groups. Interestingly, white blood cells of higher than normal (3.85 in the case group vs. 2.28 in the control group) and higher LDL levels were significantly more observed among the cases $(\mathrm{P}=0.002)$. The evalu-

Table 2. Risk factors for ischemic heart disease

\begin{tabular}{|c|c|c|c|}
\hline Risk Factor & OR & 95\% Confidence Interval & $\mathbf{P}$ \\
\hline Family history of myocardial infarction under the age of 55 & 4.12 & $1.28-13.4$ & $0.01^{*}$ \\
\hline Presence of hypertension & 2.68 & $1.07-6.66$ & $0.03^{*}$ \\
\hline Presence of diabetes & 4.16 & $1.10-15.64$ & $0.03^{*}$ \\
\hline Alcohol consumption & 0.82 & $0.23-2.82$ & 0.75 \\
\hline Smoking cigarette & 2.47 & $1.23-4.94$ & $0.01^{*}$ \\
\hline Smoking Hookah & 1.5 & $0.53-4.19$ & 0.43 \\
\hline Using Opioids & 2.09 & $0.50-8.72$ & 0.31 \\
\hline Using Methadone & 1.71 & $0.39-7.48$ & 0.47 \\
\hline Using Heroin & 5.14 & $0.24-109.15$ & 0.29 \\
\hline Using Cocaine & 3.04 & $0.12-75.99$ & 0.49 \\
\hline Using Cannabis & 1.83 & $0.51-6.56$ & 0.35 \\
\hline Using Methamphetamines & 3.08 & $0.31-30.44$ & 0.33 \\
\hline Using Tramadol & 3.18 & $0.32-16.67$ & 0.16 \\
\hline Using Benzodiazepines & 0.47 & $0.11-1.99$ & 0.31 \\
\hline Using Tricyclic Antidepressants (TCAs) & 2.02 & $0.17-22.90$ & 0.56 \\
\hline Using Buprenorphine & 0.32 & $0.31-8.11$ & 0.49 \\
\hline Using Anabolic steroids & 3.77 & $0.75-18.87$ & 0.1 \\
\hline LOW-DENSITY lipoprotein (LDL) above 130 & 2.64 & $1.31-5.32$ & $0.006^{*}$ \\
\hline
\end{tabular}

* Significant difference between case and control groups. 
ated risk factors with their Odds Ratio (OR) and p-values are provided in Table 2 .

\section{Discussion}

The purpose of this study was to determine the risk factors for ischemic heart disease and the effect of substance abuse on the incidence of this disease in patients younger than 40 years. Seventy patients with acute MI under the age of 40 and 70 healthy individuals under the age of 40 were studied as the cases and control groups, respectively. Among the underlying factors, the family history, high blood pressure, diabetes, smoking, and LDL levels above $130 \mathrm{mg} / \mathrm{dL}$ were associated with a higher risk of acute MI. However, in the present study, the use of alcohol, hookah, opium, methadone, heroin, cocaine, cannabis, amphetamine, methamphetamine, tramadol, benzodiazepine, Tricyclic Antidepressants (TCAs), buprenorphine, and anabolic steroids use was not associated with a higher risk of acute MI under 40 years of age. However, a limited number of studies were found to compare their results with our results.

In a study in 2013, it was reported that the use of opioids increases the risk of MI [20]. However, in the current study, this outcome was not seen; it seems the limited sample size of our study and the wider age range of the aforementioned study (versus patients under the age of 40 years in the present study) are among the reasons for this difference. The factors mentioned above are the underlying causes for the difference between the results of the present study and studies showing the risk of acute MI following the use of tramadol and TCAs.

\section{Conclusion}

According to the results of the present study, it seems that a positive family history of MI under the age of 55, hypertension, diabetes, smoking, and LDL levels above $130 \mathrm{mg} / \mathrm{dL}$ increase the risk of acute MI in patients under 40 years of age and consumption of alcohol, hookah, opium, methadone, heroin, cocaine, cannabis, amphetamine, methamphetamine, tramadol, benzodiazepines, TCA, Buprenorphine and anabolic steroids are not associated with an increase is the risk of MI. It should be noted that further studies in this area are recommended. The main limitation of our study was the small sample size of the groups.

\section{Ethical Considerations}

\section{Compliance with ethical guidelines}

All ethical principles are considered in this article. The participants were informed of the purpose of the research and its implementation stages. They were also assured about the confidentiality of their information and were free to leave the study whenever they wished, and if desired, the research results would be available to them. A written consent has been obtained from the subjects. principles of the Helsinki Convention was also observed. This study was approved by the Ethics in Research Committee of Alborz University of Medical Sciences (IR.ABZUMS.REC.1398.220).

\section{Funding}

This research did not receive any grant from funding agencies in the public, commercial, or non-profit sectors.

\section{Authors' contributions}

Methodology: Mohamadreza maghsoudi; Data collection: Javad Karimi; Writing - original draft: Lida Shojaei Arani; Investigation: Shahrooz Yazdani; Supervision: Kiumars Bahmani: a review of the manuscript and submitting the manuscript, Hoorvash Faraji Dana: clinical toxicology consult and review of the manuscript.

\section{Conflict of interest}

The authors declared no conflict of interest.

\section{References}

[1] Tsai WC, Wu KY, Lin GM, Chen SJ, Lin WS, Yang SP, et al. Clinical characteristics of patients less than forty years old with coronary artery disease in Taiwan: A cross-sectional study. Acta Cardiol Sin. 2017; 33(3):233-40. [DOI:10.1161/01. CIR.95.1.5]

[2] Mohseni J, Kazemi T, Maleki MH, Beydokhti H. A systematic review on the prevalence of acute myocardial infarction in Iran. Heart Views. 2017; 18(4):125-32. [DOI:10.4103/HEARTVIEWS.HEARTVIEWS_71_17] [PMID] [PMCID]

[3] Selwyn AP, Kinlay S, Libby P, Ganz P. Atherogenic lipids, vascular dysfunction, and clinical signs of ischemic heart disease. Circulation. 1997; 95(1):5-7. [DOI:10.1161/01.CIR.95.1.5] [PMID]

[4] Christoffersen M, Frikke-Schmidt R, Schnohr P, Jensen GB, Nordestgaard BG, Tybjærg-Hansen A. Visible age-related signs and risk of ischemic heart disease in the general population: A prospective cohort study. Circulation. 2014; 129(9):990 8. [DOI:10.1161/CIRCULATIONAHA.113.001696] [PMID] 
[5] Egred M, Viswanathan G, Davis GK. Myocardial infarction in young adults. Postgrad Med J. 2005; 81(962):741-5. [DOI:10.1136/pgmj.2004.027532] [PMID] [PMCID]

[6] Vedanthan R, Seligman B, Fuster V. Global perspective on acute coronary syndrome: A burden on the young and poor. Circ Res. 2014; 114(12):1959-75. [DOI:10.1161/CIRCRESAHA.114.302782] [PMID] [PMCID]

[7] Moran AE, Forouzanfar MH, Roth GA, Mensah GA, Ezzati M, Murray CJ, et al. Temporal trends in ischemic heart disease mortality in 21 world regions, 1980 to 2010 The global burden of disease 2010 study. Circulation. 2014; 129(14):1483-92. [DOI:10.1161/CIRCULATIONAHA.113.004042] [PMID] [PMCID]

[8] Hoo FK, Foo YL, Lim SM, Ching SM, Boo YL. Acute coronary syndrome in young adults from a Malaysian tertiary care centre. Pak J Med Sci. 2016; 32(4):841-5. [DOI:10.12669/ pjms.324.9689] [PMID] [PMCID]

[9] Magnusson BJ, Agnarsson U, Guðnason T, Porgeirsson G. [Acute myocardial infarction among Icelanders forty years old and younger 2005-2009. Comparison with a study carried out 1980-1984 (Icelandic)]. Laeknabladid. 2017; 103(1):11-5. [DOI:10.17992/lbl.2017.01.115] [PMID]

[10] Deora S, Kumar T, Ramalingam R, Nanjappa Manjunath C. Demographic and angiographic profile in premature cases of acute coronary syndrome: Analysis of 820 young patients from South India. Cardiovascular Diagn Ther. 2016; 6(3):1938. [DOI:10.21037/cdt.2016.03.05] [PMID] [PMCID]

[11] Tini G, Proietti G, Casenghi M, Colopi M, Bontempi K, Autore $\mathrm{C}$, et al. Long-term outcome of acute coronary syndromes in young patients. High Blood Press Cardiovasc Prev. 2017 24(1):77-84. [DOI:10.1007/s40292-017-0183-6] [PMID]

[12] Vanberg P, Atar D. Androgenic anabolic steroid abuse and the cardiovascular system. Handb Exp Pharmacol. 2010; (195):411-57. [DOI:10.1007/978-3-540-79088-4_18] [PMID]

[13] Rezkalla S, Kloner RA. Cardiovascular effects of marijuana. Trends Cardiovascular Med. 2019; 29(7):403-7. [DOI:10.1016/j. tcm.2018.11.004] [PMID]

[14] Khodneva Y, Muntner P, Kertesz S, Kissela B, Safford MM. Prescription opioid use and risk of coronary heart disease, stroke, and cardiovascular death among adults from a prospective cohort (REGARDS Study). Pain Med. 2016; 17(3):44455. [DOI:10.1111/pme.12916] [PMID] [PMCID]

[15] Kadhum M, Jaffery A, Haq A, Bacon J, Madden B. Measuring the acute cardiovascular effects of shisha smoking: A crosssectional study. JRSM Open. 2014; 5(6):2054270414531127. [DOI:10.1177/2054270414531127] [PMID] [PMCID]

[16] Sayyah M, Shirbandi K, Javanmardi F, Rahim F. A systematic review and meta-analysis of the prevalence of methamphetamine abuse in Iranian high school students. J Med Life. 2018; 11(4):262-8. [DOI:10.1111/joim.12035] [PMID]

[17] Kaye S, McKetin R, Duflou J, Darke S. Methamphetamine and cardiovascular pathology: A review of the evidence. Addiction. 2007; 102(8):1204-11. [DOI:10.1111/j.13600443.2007.01874.x] [PMID]

[18] Piano MR. Alcohol's effects on the cardiovascular system. Alcohol Res. 2017; 38(2):219-41. [PMID] [PMCID]
[19] Fauci SA, Longo DA, Kasper DL, Jameson JL, Loscalzo L, Hauser SL. Harrison's Principles of Internal Medicine 20/E (Vol.1 \& Vol.2) (ebook). 20 th ed. New York: McGrawHill Education; 2018. https://www.google.com/books/ edition/Harrison_s_Principles_of_Internal_Medici/ ID5lDwAAQBAJ?hl=en

[20] Li L, Setoguchi S, Cabral H, Jick S. Opioid use for noncancer pain and risk of myocardial infarction amongst adults. J Intern Med. 2013; 273(5):511-26. [DOI:10.1111/joim.12035] [PMID] 